\title{
Debido proceso e infancia. La participación de niños, niñas y adolescentes en el proceso judicial a la luz de los Derechos Humanos, con especial referencia al derecho a la prueba y el derecho a la sentencia motivada en clave de infancia ${ }^{1}$
}

\author{
Due Process and Childhood. \\ The Participation of Children and Adolescents in the Judicial Process in the \\ light of Human Rights, with special reference to the Right to Evidence and \\ the Right to a Reasoned Sentence from a Childhood Perspective
}

Cristian CONTRERAS RojAS ${ }^{2}$

\begin{abstract}
Resumen: Este trabajo analiza la participación de niños, niñas y adolescentes en el proceso judicial. Se parte de la base que las garantías y formas habituales empleadas en los litigios entre adultos no resultan plenamente aplicables en este caso. Ello se debe a que la vigencia efectiva de los derechos humanos de todos los niños, niñas y adolescentes puede entrar en colisión con la interpretación y aplicación usual de las garantías del debido proceso, lo que atenta contra la dignidad de los menores de edad y el principio del interés superior de niño. De esta forma, se proponen algunos ajustes al debido proceso a fin de conciliarlo con los derechos de la infancia, particularmente en cuanto al derecho a la prueba y el derecho a la sentencia motivada.
\end{abstract}

Palabras clave: Debido proceso, Infancia, Derechos Humanos

\footnotetext{
${ }^{1}$ Este trabajo forma parte del Proyecto FONDECYT de Iniciación № 11190453 titulado “La declaración testimonial de niños, niñas y adolescentes. Propuesta de un estándar normativo para su práctica y valoración", del cual el autor es Investigador Responsable. Agradezco el apoyo de la Agencia Nacional de Investigación y Desarrollo para el financiamiento del referido Proyecto.

${ }^{2}$ Abogado, Profesor de Derecho Procesal de la Facultad de Ciencias Jurídicas y Sociales de la Universidad de Talca (Chile). Doctor en Derecho por la Universitat de Barcelona, España. Miembro de la Red Chilena de Investigadores en Derecho Procesal. Correo electrónico: ccontreras@utalca.cl
} 
Abstract: This work analyzes the participation of children and adolescents in the judicial process. It is based on the assumption that the usual guarantees and forms used in litigation between adults are not fully applicable in this case. In fact, the effective enforcement of the human rights of all children and adolescents can collide with the usual interpretation and application of due process guarantees, which undermines the dignity of minors and the principle of the best interests of the child. In this way, some adjustments to due process are proposed in order to reconcile it with the rights of children, particularly regarding the right to evidence and the right to a reasoned sentence.

Keywords: Due Process, Childhood, Human Rights

\section{Introducción ${ }^{3}$}

Sin lugar a duda, los NNA han pasado a ser actores cada vez más habituales de todas las áreas del desarrollo social, lo que ha provocado su mayor intervención en procesos judiciales de distinta naturaleza, así como el desempeño de diversos roles. Esta situación ha dibujado un nuevo e interesante escenario para el devenir de la actividad jurisdiccional y representa un enorme desafío para todo el sistema de administración de justicia.

Lo anterior se debe a que no es un misterio que los procesos judiciales son diseñados por y para adultos, por lo que normalmente no hay espacios e instancias pensadas para hacer frente a la intervención de NNA, cuestión que debe analizarse a la luz de la responsabilidad que pesa sobre el Estado en cuanto a garantizar el respeto del debido proceso para todos los litigantes 4 , lo que obviamente incluye a las personas menores de edad. Esto implica transitar desde una concepción adultocéntrica de los procesos judiciales donde participan NNA hacia un diseño que permita su intervención efectiva con pleno respeto de su interés primordial y sus derechos humanos.

Dicha tarea no resulta baladí si consideramos que todo el sistema se enfrenta a la necesidad de respetar a cabalidad los derechos de la infancia en el proceso judicial. En esta perspectiva, ¿cuáles son las adecuaciones que debe realizar a la interpretación y aplicación habitual de las garantías del debido proceso cuando en un proceso judicial intervienen NNA? ¿Cuáles son los

\footnotetext{
${ }^{3}$ Tabla de abreviaturas: CADH: Convención Americana de Derechos Humanos; CADHP: Carta Africana sobre los Derechos Humanos y de los Pueblos; CDN: Convención sobre los Derechos del Niño; CEDH: Convenio Europeo de Derechos Humanos; Corte IDH: Corte Interamericana de Derechos Humanos; DUDH: Declaración Universal de Derechos Humanos; ISN: interés superior del niño; NNA: niños, niñas y adolescentes; PIDCP: Pacto Internacional de Derechos Civiles y Político.

${ }^{4}$ Quispe (2010), p. 223.
} 
LA PARTICIPACIÓN DE NIÑOS, NIÑAS Y ADOLESCENTES EN EL PROCESO JUDICIAL A LA LUZ DE LOS DERECHOS HUMANOS, CON ESPECIAL REFERENCIA AL DERECHO A LA PRUEBA Y EL DERECHO A LA SENTENCIA MOTIVADA EN CLAVE DE INFANCIA

mínimos exigibles o deseables para que el proceso pueda seguir siendo calificado como "debido" y respetuoso de los derechos humanos de las personas menores de edad que participan en él?

Con dicho afán, en este trabajo se buscará dar cuenta y reafirmar la necesidad de configurar un debido proceso para NNA, pues no solo las garantías que lo integran posibilitan su adecuación frente a determinados colectivos, sino también porque lo contrario implicaría dejar de reconocer tanto las particularidades propias de este grupo etario como la necesidad de protección y resguardo que le cabe a los órganos estatales en este ámbito. Para ello, se tendrán en cuenta distintos pronunciamientos de la Corte IDH en relación con el debido proceso y la infancia, se destacará la función de la dignidad humana y al principio del ISN, para finalmente avanzar propuestas concretas respecto a dos aspectos específicos del debido proceso: el derecho a la prueba y el derecho a la sentencia motivada, todo ello a la luz de los derechos humanos.

\section{Una breve mirada a los fundamentos y la función instrumental del debido proceso}

Habiendo transcurrido más de ochocientos años desde su primera manifestación expresa contenida en el numeral 39 de la Carta Magna inglesa, de 15 de junio de $1215^{5}$ 一, obligado resulta reconocer que el debido proceso es una institución que se ha desarrollado, evolucionado y difundido en diversos ordenamientos jurídicos integrantes tanto del civil law como del common $l a w^{6}$. En efecto, actualmente es un componente esencial del plexo de derechos fundamentales reconocido por una serie de instrumentos internacionales ${ }^{7} \mathrm{y}$ al mismo tiempo consagrado con rango constitucional por los distintos Estados ${ }^{8}$.

Vale la pena recordar que si bien hoy el debido proceso comprende un conjunto de garantías básicas de que gozan todas y cada una de las personas que intervienen en contextos de

\footnotetext{
${ }^{5}$ Disposición que expresamente señalaba: “39. No freemen shall be taken or imprisoned or disseised or exiled or in any way destroyed, nor will we go upon him nor send upon him, except by the lawful judgment of his peers or by the law of the land". Por cierto, se ha indicado "que la frase "due process of law" es una variación de la contenida en la Magna Carta Inglesa de 1215 «per legem terrae», «by the law of the land»". Esparza (1995), p. 71.

${ }^{6}$ Sobre un detallado y completo tratamiento sobre el origen del debido proceso en el common law y civil law, ver por todos, Quispe (2010), pp. 34-104. Asimismo, ver Hoyos (2004), pp. 6-13. Por su parte, una excelente referencia al origen medieval del debido proceso y su introducción en el sistema estadounidense puede encontrarse en García (2006a), pp. 652 y ss.

${ }^{7}$ Así se ha consagrado en los arts. 8 y 10 de la DUDH; en el art. 14 del PIDCP; en el art. 6 del CEDH; en el art. 8 de la CADH; y en el art. 7 de la CADHP.

${ }^{8}$ En efecto, más allá del nomen juris con que las diversas Constituciones se refieren a este derecho fundamental, es claro que se trata de lo mismo. En este sentido, a modo ejemplar, la Constitución de la Nación Argentina en su art. 18 se refiere a la garantía de "la defensa en juicio de la persona y de los derechos"; el art. 29 de la Constitución Política de la República de Colombia expresa: "El debido proceso se aplicará a toda clase de actuaciones judiciales y administrativas"; la Constitución Española se refiere a "tutela judicial" (artículo 24.1) o el art. $19 \mathrm{~N}^{\circ} 3$ inc. 6 de la Constitución Política chilena que hace alusión a "un procedimiento y una investigación racionales y justos".
} 
adjudicación sin distinciones o discriminaciones de ningún tipo (lo que obviamente incluye al factor etario), su origen no estuvo marcado por la concepción de normas procedimentales. Más bien, constituyó un intento por limitar el poder regio absoluto y omnímodo que marcaba el devenir de las sociedades europeas medievales, de manera de proteger los derechos esenciales de ciertos grupos de personas mediante la fijación de cortapisas al actuar arbitrario o despótico del detentador del poder estatal ${ }^{9}$.

Ese objetivo original de protección de los ciudadanos frente a las arbitrariedades del soberano permite afirmar que el reconocimiento y vigencia del debido proceso es de capital importancia para el respeto del resto de derechos fundamentales que poseen todos los ciudadanos, incluyendo, obviamente, a aquellos propios de la infancia. Es la observancia de todos estos derechos la que permite el desarrollo democrático de la vida en sociedad, más aún si pensamos que el debido proceso tiene un impacto directo en la forma en que se resuelven los conflictos jurídicos en los que está en juego uno o más derechos de las personas. De ahí que no es baladí la misión que se ha impuesto a los Estados en el sentido de crear las condiciones para que las personas puedan acceder al sistema de administración de justicia y participar de forma activa, legítima y con igualdad en la construcción de la decisión que les concierne ${ }^{10}$, para finalmente obtener una solución —ojalá- justa del órgano jurisdiccional. Por cierto, este rol estatal no es voluntario ni menos una concesión graciosa de la autoridad, ya que le viene impuesto, a nivel regional, por el art. 1.1 de la $\mathrm{CADH}$, de donde se desprende que el Estado tiene la obligación de adoptar todas las medidas oportunas para proteger y preservar los derechos humanos ${ }^{11}$.

El debido proceso está dado por el conjunto de garantías básicas y esenciales que actualmente se estiman eficaces para la protección de los derechos de todos los justiciables y que a la vez permiten crear y mantener el escenario para que el proceso se lleve a cabo de una forma racional y equitativa, de modo que culmine con una decisión justa ${ }^{12}$ y legítima ${ }^{13}$.

Así, se ha entendido que la observancia de un estándar básico común a todo tipo de proceso judicial que permita calificarlo como “debido”, más allá de las diferencias y exigencias en su

\footnotetext{
${ }^{9}$ Fajardo (2014), p. 18.

${ }^{10}$ Couture (1988), p. 29.

${ }^{11}$ Lo que ha sido expresamente señalado en estos términos por la Corte IDH. Corte IDH, Caso de la Masacre de las Dos Erres vs. Guatemala, de 24 de noviembre de 2009, párr. 184.

12 García y Contreras (2013), p. 257. En efecto, la Corte IDH ha resaltado el estrecho vínculo existente entre el debido proceso y la justicia. Corte IDH, Opinión Consultiva OC-21/14, de 19 de agosto de 2014, párr. 109.

${ }^{13}$ Quispe (2010), p. 33.
} 
aplicación derivadas de su particular naturaleza (penal, civil, laboral, familiar u otra), es requisito sine qua non para la consecución de decisiones justas ${ }^{14}$. Por ello, parece completamente acertado sostener que el debido proceso "es un derecho fundamental complejo de carácter instrumental"15, toda vez que se trata de una garantía de efectividad del resto de los derechos humanos, los que solo van a tener posibilidades de ser reconocidos y tutelados al interior del contexto judicial si el debido proceso tiene una vigencia efectiva. Por ende, no es de extrañar que el rol que le corresponde desempeñar a este derecho haya impulsado a Quispe a sostener que "el derecho al debido proceso forma parte [del] núcleo duro de los derechos humanos" 16.

Ahora bien, a nivel interamericano, el debido proceso legal reconocido por el art. 8 de la CADH consiste en un conjunto de condiciones o requisitos mínimos que deben cumplirse para que aquellas personas que someten sus derechos y obligaciones de cualquier naturaleza al conocimiento y decisión de todo tipo de autoridades estatales ${ }^{17}$, estén en posición de defenderse adecuadamente ante sus actos, sea en instancias administrativas, legislativas o judiciales ${ }^{18}$. Por consiguiente, el debido proceso viene a asegurar el respeto de los órganos estatales hacia la persona que acude ante ellos en pos del esclarecimiento de un derecho que afirma corresponderle o una obligación que debe soportar, respeto que primeramente se manifiesta sobre los derechos que le corresponden al ciudadano al interior del proceso, durante toda su sustanciación, pero que obviamente también tendrá un influjo positivo en relación con aquellos derechos que deben ser dilucidados por la autoridad en la decisión del asunto ${ }^{19}$.

\section{La dignidad humana como elemento básico justificante de la adecuación del debido proceso a los derechos de la infancia}

A partir del rol instrumental y garantista que le cabe al derecho al debido proceso en el reconocimiento y respeto del resto de derechos humanos, es claro que el proceso judicial no puede constituirse en una fuente de afectación de estos. Dicho de otra forma, en la configuración

\footnotetext{
14 Sobre este aserto, Taruffo ha señalado que: “...la giustizia della decisione assume la forma di un algoritmo che ricomprende e collega tre ordini di valori. I tre criteri ai quali si allude sono i seguenti: a) correttezza della scelta e dell'interpretazione della regola giuridica applicabile al caso; b) accertamento attendibile dei fatti rilevanti del caso; c) impiego di un procedimento valido e giusto per giungere alla decisione". Taruffo (1997), p. 317.

${ }^{15}$ Agudelo (2005), p. 90.

${ }^{16}$ Quispe (2010), p. 575.

${ }^{17}$ Carmona (2014), p. 52.

${ }^{18}$ Corte IDH, Opinión Consultiva OC-9/87, de 6 de octubre de 1987, párr. 28. En el mismo sentido, Corte IDH, Opinión Consultiva OC-16/99, de 1 de octubre de 1999, párr. 69; Corte IDH, Caso Baena Ricardo y otros vs. Panamá, de 2 de febrero de 2001, párr. 124; Corte IDH, Caso Familia Pacheco Tineo vs. Estado Plurinacional de Bolivia, de 25 de noviembre de 2013, párr. 130; Corte IDH, Opinión Consultiva OC-21/14, de 19 de agosto de 2014, párr. 109; Corte IDH, Caso Maldonado Ordoñez vs. Guatemala, de 3 de mayo de 2016, párr. 71.

${ }^{19}$ Quispe (2010), p. 68. En esta perspectiva, Corte IDH, Opinión Consultiva OC-16/99, de 1 de octubre de 1999, párr. 118.
} 
de los procesos no debe haber espacio para la vulneración de los derechos cuya protección es su finalidad última, más aún cuando este instrumento de resolución pacífica de conflictos está diseñado para satisfacer las necesidades de las personas y de las sociedades en este ámbito ${ }^{20}$.

Dicho aserto debe ser reafirmado y robustecido cuando entre los miembros y grupos que forman parte de las distintas sociedades se constate la presencia de individuos situados en una posición debilitada, circunstancia que per se amerita replantearse tanto el diseño de los procesos judiciales como el sentido en que se interpretan y la intensidad con que aplican los distintos componentes del debido proceso (entre los que se encuentra el derecho a la prueba o a la sentencia motivada), de modo de llevar a cabo los ajustes concretos que sean pertinentes a fin de cumplir con el objetivo final de resguardo y protección de todos los derechos de los justiciables.

Lo anterior radica principalmente en que el proceso judicial, tanto desde una visión general y abstracta, como desde la perspectiva de la decisión de cada caso concreto, debe servir de herramienta para el reconocimiento y respeto de la dignidad de las personas, en el entendido que el conjunto de garantías y derechos que integran la noción de debido proceso supone una aplicación particular del valor supremo de la dignidad humana21.

De esta manera, se ha sostenido que el debido proceso permite que las personas que se verán afectadas por las decisiones gubernamentales, tengan la posibilidad de participar activamente en la instancia en que se tomará esa decisión, oportunidad que significa un reconocimiento de su dignidad ${ }^{22}$. Por tanto, teniendo en cuenta que obviamente la dignidad es la misma para todas las personas y que el debido proceso es una expresión de ella, las garantías que lo componen deben constituir una manifestación de un trato igualitario y no discriminatorio hacia todos aquellos que intervienen en un proceso.

Vale decir, para el respeto y protección de la dignidad de los intervinientes en juicio, se torna imprescindible que las garantías del debido proceso sean interpretadas y aplicadas en clave de evitar que intraprocesalmente se repliquen las diferencias que pueden existir extramuros, debido a razones sociales, económicas, educacionales u otras, de manera que todos los litigantes estén en condiciones de hacer valer sus derechos no solo con las mismas reglas formales y

\footnotetext{
${ }^{20}$ Priori (2003), pp. 273-274.

${ }^{21}$ Letelier (2013), pp. 147-148. También, Pinto (2019), pp. 46-51. En esta perspectiva, se ha apuntado muy acertadamente que la dignidad humana es el sustento o fundamento esencial del ISN. Hoyos (2019), pp. 55-62.

22 Oteiza (2003), p. 8.
} 
sustantivas, sino con idénticas posibilidades reales ${ }^{23}$. De lo contrario, la igualdad protección de la ley en el ejercicio y defensa de los derechos quedará reducida a una simple declaración bienintencionada carente de eficacia práctica.

En esta línea, la Corte IDH ha sostenido que solo existirá debido proceso legal cuando todos los litigantes de un caso concreto puedan hacer valer sus derechos y defender sus intereses de forma efectiva y en condiciones de igualdad ${ }^{24}$. Esta situación de igualdad ante la ley y los tribunales solo se conseguirá cuando el proceso sea capaz de reconocer y resolver los factores de inequidad real que existan entre los justiciables, de modo que se deben disponer y ejecutar todas las medidas de compensación para reducir o eliminar los obstáculos que impidan o reduzcan la defensa eficaz de los derechos de las partes. De lo contrario, ellas no habrán tenido un verdadero acceso a la justicia ni tampoco al goce de las garantías del debido proceso en paridad de condiciones 25 .

Por consiguiente, el trato igualitario que deben recibir todas las personas al interior del proceso no es óbice para que las instituciones estatales adopten medidas específicas y diferenciadas para que el debido proceso se cumpla de manera efectiva respecto de aquellos que se encuentran en una situación particular (como ocurre en el caso de NNA) ${ }^{26}$. Muy por el contrario, ello exige que dichas acciones se lleven a cabo, de manera de eliminar todos los desequilibrios existentes. Así, tratándose de personas menores de edad, no cabe duda que el debido proceso debe ajustarse a ellas, a fin de protegerlas en todas las fases de su desarrollo 27. De lo contrario, se estaría situando en una posición aún más desmedrada a un colectivo que por definición requiere que se adopten todos los resguardos necesarios a su respecto.

De esta forma, no puede pensarse que el trato diferenciado que reciban los NNA al interior del proceso judicial, y las consecuentes adecuaciones a las garantías del debido proceso que deban realizarse, constituyen un trato discriminatorio y perjudicial para los adultos que intervengan en el mismo proceso, tal como expresamente lo ha señalado la Corte IDH:

Se puede concluir, que en razón de las condiciones en las que se encuentran los niños, el trato diferente que se otorga a los mayores y a los menores de edad no es per se discriminatorio,

\footnotetext{
${ }^{23}$ Carmona (2014), p. 35.

${ }^{24}$ Corte IDH, Opinión Consultiva OC-16/99, de 1 de octubre de 1999, párr. 117.

${ }^{25}$ Corte IDH, Opinión Consultiva OC-16/99, de 1 de octubre de 1999, párr. 119. También ver, Corte IDH, Opinión Consultiva OC17/2002, de 28 de agosto de 2002, párr. 97.

${ }^{26}$ Carmona (2014), p. 35.

${ }^{27}$ Así, se ha indicado que tratándose de los NNA "el principal factor de vulnerabilidad es su edad, lo que no impide que además de ésta, tengan características adicionales que los coloquen en una situación de vulnerabilidad agravada, por ser adicionalmente mujer, indígena, tener una discapacidad o migrante". Cumbre Judicial Iberoamericana (2014), p. 17.
} 
en el sentido proscrito por la Convención. Por el contrario, sirve al propósito de permitir el cabal ejercicio de los derechos reconocidos al niño. Se entiende que, en virtud de los artículos 1.1 y 24 de la Convención, los Estados no pueden establecer diferenciaciones que carezcan de una justificación objetiva y razonable y no tengan como objeto único, en definitiva, el ejercicio de los derechos establecidos en aquélla ${ }^{28}$.

Lo anterior es posible mediante el fenómeno de especificación de los derechos fundamentales. Este permite que ciertos derechos humanos sean reconocidos con mayor precisión y fuerza para determinados colectivos, debido precisamente al contexto de desigualdad en que ellos se encuentran y que les genera una situación de debilidad que no solo debe ser protegida, sino corregida por el sistema jurídico en su conjunto. Con esto se busca equiparar a todas las personas en el disfrute de sus derechos ${ }^{29}$, tal como resulta necesario respecto de aquellos que se encuentran en la etapa de infancia o adolescencia ${ }^{30}$.

Con ese afán, no hay que perder de vista que el debido proceso está constituido por una serie de componentes o garantías que se presentan como un conjunto de parámetros o estándares básicos y generales que se estiman como el mínimo aceptable para el devenir de los procesos judiciales ${ }^{31}$, características que constituyen una ventaja en la tarea de especificación o adaptación de su contenido ante la participación de NNA en el proceso, sin que ello signifique desfigurar el contenido esencial de este derecho fundamental y afectar con ello los derechos del resto de intervinientes. De hecho, ha sido la propia Corte IDH la que ha destacado que el carácter irreductible y estricto de los principios y actos del debido proceso legal no le impiden ampliarse a la luz de nuevos avances en materia de derechos humanos ${ }^{32}$. Por otra parte, también se ha subrayado que el debido proceso se destaca por su proporcionalidad, la que permite que sus componentes se apliquen con distinta intensidad dependiendo de diversos factores ${ }^{33}$, entre los que obviamente debe incluirse a las características particulares de las personas que intervienen en el proceso.

Sea como fuere, habrá que preguntarse cuáles son los mínimos exigibles o deseables para que el proceso judicial pueda seguir siendo calificado de "debido" cuando en él intervienen personas menores de edad. En este sentido, se habla de la existencia de un perfil mínimo del derecho al

\footnotetext{
${ }^{28}$ Corte IDH, Opinión Consultiva OC-17/2002, de 28 de agosto de 2002, párr. 55. También ver, Corte IDH, Caso Instituto de Reeducación del Menor vs. Paraguay, de 2 de septiembre de 2004, párr. 209; Corte IDH, Caso Mendoza y Otros vs. Argentina, de 14 de mayo de 2013, párr. 146.

${ }^{29}$ Letelier (en prensa), p. 1.

${ }^{30}$ Sobre este tema, Bobbio afirmó en su momento que "[e]sta especificación se ha producido bien respecto al género, bien respecto a las distintas fases de la vida, bien teniendo en cuenta la diferencia entre estado normal y estados excepcionales en la existencia humana". Bobbio (1991), p. 110.

${ }^{31}$ Vargas y Fuentes (2019), p. 148.

${ }^{32}$ Corte IDH, Caso Mendoza y Otros vs. Argentina, de 14 de mayo de 2013, párr. 148.

${ }^{33}$ Duce et al. (2011), p. 184.
} 
debido proceso que serviría para contrastar la estructuración de todos los procedimientos, umbral que no impone una configuración técnica idéntica para todos ellos, sino que lo que busca es la adecuación del proceso al derecho material ${ }^{34}$. Dicho de otra manera, resulta indiscutible que las formas del proceso no pueden anteponerse a la tutela de los derechos sustanciales que están en juego, pues dicha protección es el objetivo principal del proceso. De esa manera, el proceso será debido cuando permita alcanzar la finalidad esencial para la que fue concebido, con pleno respeto de los derechos de todos los justiciables.

\section{Un proceso debido para la niñez: no hay debido proceso sin respeto irrestricto hacia los derechos de la infancia}

Como se ha indicado, las garantías del debido proceso deben servir para asegurar una posición de igualdad jurídica para la defensa de los derechos de todos los litigantes, lo que podrá o no estar unido a una aplicación simétrica de las mismas reglas procesales para todos ellos. Esto dependerá de la situación de (des)igualdad real que exista entre los justiciables en el contexto extraprocesal, pues los componentes del debido proceso deben emplearse para crear las mismas condiciones y posibilidades para el ejercicio de los derechos al interior del juicio, de modo que la aplicación de reglas parejas y estrictas para todas las partes involucradas debe ceder ante este fin último perseguido.

En ese sentido, no resulta aceptable que la aplicación rígida del contenido del debido proceso genere que los NNA se vean desfavorecidos al interior del proceso judicial a raíz de su condición etaria. Esta cuestión queda claramente de manifiesto al apreciar los instrumentos jurídicos que constituyen el corpus iuris internacional en materia de infancia ${ }^{35}$ y donde se abordan varios aspectos específicos de la participación procesal de los NNA, tal como ocurre, v. gr. con la CDN, las Reglas de Beijing, las CADH y el PIDCP ${ }^{36}$. Todo este entramado normativo internacional es el que está llamado a iluminar la interpretación y aplicación de las garantías del debido ante la

\footnotetext{
${ }^{34}$ Marinoni et al. (2018), p. 85.

${ }^{35}$ Ibáñez (2010), p. 17.

${ }^{36}$ En efecto, los artículos 37 y 40 de la CDN se refieren a los derechos de los niños privados de libertad y a las garantías del niño infractor de la ley penal. A su turno, las Reglas de Beijing (Reglas mínimas para la administración de la justicia de menores delincuentes) abordan las facultades discrecionales del tribunal atendidas las necesidades especiales de los menores (art. 6), las garantías procesales básicas de los niños, como el derecho a presunción de inocencia, notificación, asesoramiento letrado, de recho a interrogar y confrontar los testigos y de apelar en contra de la sentencia (art. 7), además de disponer la protección de su intimidad (art. 8). Por su parte, la CADH dispone que los menores procesados penalmente deberán estar separados de los adultos y llevados antes tribunales especializados con la mayor celeridad posible (art. 5.5). Finalmente, el PIDCP señala que los menores proces ados penalmente deberán estar separados de los adultos y que deberán ser llevados ante los tribunales con la mayor celeridad po sible (art. 10.2 letra b), que las sentencias no tendrán publicidad cuando lo exija el interés de los menores de edad (art. 14.1) y que en los procedimientos penales aplicables a los menores de edad se tendrá en cuenta su carácter de tales y la importancia de estimular su readaptación social (art. 14.4).
} 
participación de niños, niñas y adolescentes en el proceso, a fin de dar paso a la plena vigencia y respeto de todos sus derechos humanos, teniendo como punto de partida que es el debido proceso el que debe ajustarse a los derechos de la infancia y no al revés.

En esta perspectiva, y como telón de fondo de los derechos de la infancia, los distintos instrumentos internacionales parten por reconocer que todos los niños y niñas tienen derecho a las medidas de protección que su condición de tales haga necesarias, ya sea que ellas provengan de la familia, la sociedad o el Estado 37.

Obviamente dichas medidas también deben expresarse durante el desarrollo de los procesos judiciales, ámbito en el cual será el Estado el único responsable de emprender las acciones de carácter administrativo, legislativo o judicial que sean oportunas para brindar de manera efectiva la protección requerida.

En esta línea, la Corte IDH ha señalado expresamente que —atendido lo previsto por el preámbulo de la CDN y el art. 19 de la $\mathrm{CADH}$ - la necesidad de adoptar esas medidas o cuidados hacia la infancia emana desde la situación específica en la que se encuentran los niños, dada la debilidad, inmadurez, vulnerabilidad o inexperiencia que los caracteriza ${ }^{38}$. En este sentido, la adopción de estas prevenciones corresponde a la familia, la comunidad, la sociedad o el Estado al que pertenece el niño ${ }^{39}$ — dependiendo del ámbito concreto en que este ejerza sus derechos, quienes deben tender a protegerlos integralmente con miras a lograr el pleno desarrollo de sus capacidades, de manera autónoma y libre ${ }^{40}$.

Se ha agregado que esta protección especial debe ser entendida como un derecho adicional y complementario a los demás derechos que la CADH reconoce a toda persona ${ }^{41}$, correspondiendo al Estado una posición de garante que le genera mayor cuidado y responsabilidad, así como la

\footnotetext{
${ }^{37}$ Así se señaló expresamente en el art. 25.2 de la Declaración Universal de Derechos del Hombre: “La maternidad y la infancia tienen derecho a cuidados y asistencia especiales". Posteriormente ello ha sido replicado por la Declaración de los Derechos del Niño donde se indica: “Principio 2. El niño gozará de una protección especial...”; y más tarde refrendado en el preámbulo de la CDN, donde se dispone que "la infancia tiene derecho a cuidados y asistencia especiales"."; el art. 24.1 del PIDCP: "Todo niño tiene derecho, sin discriminación alguna, a las medidas de protección que su condición de menor requiere, tanto por parte de su fam ilia como de la sociedad y del Estado"; el art. 19 de la CADH: "Derechos del Niño. Todo niño tiene derecho a las medidas de protección que su condición de menor requiere por parte de su familia, de la sociedad y del Estado"; y el art. 16 del Protocolo Adicional a la Convención Americana sobre Derechos Humanos en materia de Derechos Económicos, Sociales y Culturales: “Derecho de la niñez. Todo niño sea cual fuere su filiación tiene derecho a las medidas de protección que su condición de menor requieren por parte de su familia, de la sociedad y del Estado". Sobre esta materia, ver, Ibáñez (2010), pp. 20-23.

${ }^{38}$ Corte IDH, Opinión Consultiva OC-17/2002, de 28 de agosto de 2002, párrs. 60 y 93.

${ }^{39}$ Corte IDH, Caso Furlan y Familiares vs. Argentina, de 31 de agosto de 2012, párr. 125. También ver, Corte IDH, Caso Mendoza y Otros vs. Argentina, de 14 de mayo de 2013, párr. 140.

${ }^{40}$ Corte IDH, Caso Ramírez Escobar y Otros vs. Guatemala, de 9 de marzo de 2018, párr. 196.

${ }^{41}$ Corte IDH, Caso de la Masacre de las Dos Erres vs. Guatemala, de 24 de noviembre de 2009, párr. 184. Asimismo, Corte IDH, Caso González y Otras (“Campo Algodonero") vs. México, de 16 de noviembre de 2009, párr. 408.
} 

REFERENCIA AL DERECHO A LA PRUEBA Y EL DERECHO A LA SENTENCIA MOTIVADA EN CLAVE DE INFANCIA

necesidad de tomar medidas especiales inspiradas en el $\mathrm{ISN}^{42}$, para lo cual es imprescindible ponderar las características de la situación concreta en que se encuentre el niño o niña que requiere protección ${ }^{43}$. Por consiguiente, "el proceso tiene que estar adaptado a las niñas o niños y ser accesible para ellos"44, especialmente cuando se trate de procesos, judiciales o administrativos, en los que se resuelva acerca sus derechos ${ }^{45}$. De ahí que se haya sostenido que los derechos del niño conllevan un deber prestacional para el Estado, el que debe inspirar las políticas públicas en torno a la infancia y permitir la participación de los NNA en todas las áreas del acontecer social y ciudadano ${ }^{46}$.

En suma, aparece perfectamente como justificado y exigible la aplicación diferenciada de los elementos del debido proceso tratándose de NNA, pues se ha reconocido expresamente a nivel internacional que este grupo etario requiere una especial protección dentro de los procesos judiciales. Eso se debe a que no están en condiciones de intervenir en él tal como lo hace un adulto, de modo que aplicar el debido proceso sin atender a esta diferencia básica será motivo de inequidades e injusticias, lo que ha sido claramente graficado por la Corte IDH:

(...) la protección especial derivada del artículo 19 de la Convención implica que la observancia por parte del Estado de las garantías de debido proceso se traduce en algunas garantías o componentes diferenciados en el caso de niñas, niños y adolescentes, que se fundan en el reconocimiento de que su participación en un proceso no se da en las mismas condiciones que un adulto. El sistema de justicia adaptado a las niñas, niños y adolescentes importará que exista una justicia accesible y apropiada a cada uno de ellos, que tome en consideración no solo el principio del interés superior, sino también su derecho a la participación con base en sus capacidades en constante evolución, conforme a su edad, grado de madurez y nivel de comprensión, sin discriminación alguna. En definitiva, tal y como lo ha sostenido anteriormente esta Corte, si bien el debido proceso y sus correlativas garantías son aplicables a todas las personas, en el caso de las niñas, niños y adolescentes, el ejercicio de aquéllos supone, por las condiciones especiales en las que se encuentran, la adopción de ciertas medidas específicas con el propósito de asegurar un acceso a la justicia en condiciones de igualdad, garantizar un efectivo debido proceso y velar por que el interés superior se erija en una consideración primordial en todas las decisiones administrativas o judiciales que se adopten ${ }^{47}$.

\footnotetext{
${ }^{42}$ Corte IDH, Caso Comunidad Indígena Yakye Axa vs. Paraguay, de 17 de junio de 2005, párr. 172.

${ }^{43}$ Corte IDH, Caso Furlan y Familiares vs. Argentina, de 31 de agosto de 2012, párr. 126. También ver, Corte IDH, Caso Mendoza y Otros vs. Argentina, de 14 de mayo de 2013, párr. 141.

${ }^{44}$ Corte IDH, Opinión Consultiva OC-21/14, de 19 de agosto de 2014, párr. 114.

${ }^{45}$ Corte IDH, Caso Mendoza y Otros vs. Argentina, de 14 de mayo de 2013, párr. 144.

${ }^{46}$ Cillero (2007), p. 130.

${ }^{47}$ Corte IDH, Caso V.R.P., V.P.V. y Otros vs. Nicaragua, de 8 de marzo de 2018, párr. 158.
} 


\section{El principio del interés superior del niño como modulador de los componentes del debido proceso}

Dentro del conjunto de cuerpos normativos internacionales que reconocen, aseguran y protegen los derechos fundamentales de NNA, la CDN desempeña un rol de soporte y piedra angular de todo el sistema. Esto se debe —además de que se trata de un instrumento específico en que se contiene un catálogo muy amplio de derechos- a que en esta convención se refuerza la protección de los niños como plenos sujetos de derechos humanos, a quienes no solo les corresponde los derechos comunes a todas las personas, sino también los específicos que derivan de su condición de tal ${ }^{48}$. De esta forma, la perspectiva sobre la infancia que se incorporó a partir de la CDN motivó un vuelco en la consideración jurídica de los NNA, que pasaron desde ser objeto de simple cuidado y tutela a ser vistos como plenos ciudadanos, destinatarios y titulares de sus propios derechos y obligaciones ${ }^{49}$, es decir, se evolucionó hacia la doctrina de la protección integral del niño $0^{50}$.

Ahora bien, ya está plenamente establecido que dentro de los principios rectores que se deben aplicar y respetar en toda situación que involucre a NNA, el principio del ISN consagrado en el art. 3.1 de la $\mathrm{CDN}$ - ocupa un lugar central, pues se funda en la dignidad humana ${ }^{51}$ y está llamado a fijar los lineamientos generales de actuación de todos los actores estatales y sociales respecto a la infancia en cualquier ámbito ${ }^{52}$. En esto se incluye, por cierto, aquello que tiene relación con la labor de adecuar las garantías procesales, de modo que tanto este derecho como todos los derechos de los NNA sean efectivamente respetados, resguardados y protegidos ${ }^{53}$.

Si bien mucho se ha destacado el carácter de concepto jurídico indeterminado que caracteriza al interés superior del niño — con todo lo dulce y agraz que deriva de esa condición — ${ }^{54}$, no hay duda de que este principio solo se va a entender cumplido y respetado cuando en cada situación

\footnotetext{
${ }^{48}$ Aguilar (2008), p. 228.

${ }^{49}$ Ravetllat y Pinochet (2015), p. 911.

${ }^{50}$ Domínguez (2019), p. 11. También ver, Basset (2019), pp. 66-73.

${ }^{51}$ Así lo ha señalado expresamente la Corte IDH: Corte IDH, Opinión Consultiva OC-17/2002, de 28 de agosto de 2002, párr. 56; Corte IDH, Caso Bulacio vs. Argentina, de 18 de septiembre de 2003, párr. 134; Corte IDH, Caso Furlany Familiares vs. Argentina, de 31 de agosto de 2012, párr.126; Corte IDH, Caso Mendoza y Otros vs. Argentina, de 14 de mayo de 2013, párr. 142; Corte IDH, Caso Familia Pacheco Tineo vs. Estado Plurinacional de Bolivia, de 25 de noviembre de 2013, párr. 218; Corte IDH, Caso Ramírez Escobar y Otros vs. Guatemala, de 9 de marzo de 2018, párr. 156; y Corte IDH, Caso Atala Riffo y Niñas vs. Chile, de 24 de febrero de 2012, párr. 108.

${ }^{52}$ Baeza (2001), p. 356. En el mismo sentido: Rivero (2007), p. 80. Igualmente, Comité de los Derechos del Niño (2013), párr. 14 letra a).

53 Poder Judicial de la República de Chile (2020), p. 40.

54 Rivero (2007), pp. 101-108. Ver también, Ravetllat (2018), p. 1329; Escobar y Hernández (2018), pp. 62-75.
} 
concreta exista una satisfacción integral de los derechos del NNA ${ }^{55}$, ya que mediante el ISN se busca garantizar el disfrute pleno y efectivo de todos los derechos de la infancia y el desarrollo holístico del niño ${ }^{56}$. De esta forma, para la solución de los problemas en que se vea envuelto y afectado un menor de edad, se debe buscar la máxima concreción conjunta de todos sus derechos, los que deben ser privilegiados respecto de otros intereses que se encuentren en juego. Con este objetivo, se ha sostenido muy acertadamente que el ISN debe ser considerado una fuente de información, a la vez que un instrumento de integración e interpretación, no solo de las normas e instituciones jurídicas que están vinculadas con él, sino también en la cotidianidad de las diversas instituciones y relaciones humanas, en todos los niveles ${ }^{57}$. De esta forma, el ISN se constituye en un marco de referencia para la interpretación y aplicación de todos los derechos de la infancia ${ }^{58}$, que solo se podrán considerar plenamente concretados cuando se respete su interés superior y viceversa.

En concreto, el principio del ISN exige que todas las autoridades estatales tengan en cuenta el respeto y protección integral de los derechos de NNA al momento de adoptar tanto políticas públicas como decisiones particulares ${ }^{59}$. De esta forma, este principio no puede considerarse una simple orientación general inspiradora de las actuaciones estatales, sino que, muy por el contrario, constituye una fuente de obligaciones y limitaciones que no pueden ser desatendidas si lo que se pretende es dar completa efectividad y satisfacción a los derechos de NNA ${ }^{60}$.

Además de ello, no puede olvidarse que el ISN es en sí mismo una norma de procedimiento61, de modo que las decisiones que refieran a este aspecto deben evidenciar claramente que este principio ha sido tomado en cuenta, debiendo adoptarse salvaguardas procesales para las necesidades particulares del niño ${ }^{62}$. En específico, esto debe implicar el tránsito desde una concepción adultocéntrica de los procesos judiciales donde participen NNA a un diseño ideado para garantizar y permitir su intervención efectiva con pleno respeto de su interés primordial y sus derechos humanos ${ }^{63}$. Así, resulta evidente que los jueces están obligados a observar y hacer

\footnotetext{
${ }_{55}^{55}$ Cillero (2007), p. 140.

${ }^{56}$ Comité de los Derechos del Niño (2013), párr. 4.

${ }^{57}$ Ravetllat y Pinochet (2015), p. 905. En este sentido, Domínguez (2019), pp. 13-14.

${ }^{58}$ Cumbre Judicial Iberoamericana (2014), p. 28.

59 Escobar y Hernández (2018), p. 57. En términos similares, Cumbre Judicial Iberoamericana (2014), p. 29; Pinto (2019), pp. 7679.

${ }^{60}$ Cillero (2007), p. 133. Esta idea también ha sido reforzada por la Corte IDH: Corte IDH, Caso de la Masacre de las Dos Erres vs. Guatemala, de 24 de noviembre de 2009, párr. 184; y Corte IDH, Caso González y Otras ("Campo Algodonero") vs. México, de 16 de noviembre de 2009, párr. 408.

${ }^{61}$ Lo que ha sido destacado por la Corte IDH. Corte IDH, Caso Ramírez Escobar y Otros vs. Guatemala, de 9 de marzo de 2018, párr. 196.

${ }^{62}$ Comité de los Derechos del Niño (2013), párrs. 6 letra b) y 85.

${ }^{63}$ Aguilar (2008), pp. 229-230.
} 
efectivo el ISN en todas las etapas del proceso en que ellos participen ${ }^{64}$, sin importar el tipo o la naturaleza del procedimiento judicial o el rol concreto que desempeñen los niños en el mismo, ya sea, como partes directas o terceros colaboradores 65 .

Empero, no puede dejar se considerarse que la aplicación del ISN a una situación específica no es algo que se pueda llevar a cabo uniforme y mecánicamente respecto a todos los niños. La determinación del contenido concreto del ISN de cada NNA implica un trabajo de argumentación y colaboración serio de aquellos que intervengan en el proceso, de manera que el sentenciador cuente con todos los insumos que sean pertinentes y adecuados para establecer dicho interés superior y justificar el trato diferenciado que, de ser menester, se llevará a cabo, sin incurrir en arbitrariedades de ningún tipo ${ }^{66}$. Es decir, no existe una noción omnicomprensiva del interés superior de todos los NNA, sino que este principio general deberá ser llenado de contenido para el caso particular67, de acuerdo con las características propias de desarrollo de cada niño y el contexto social, cultural, económico, etc. en que se desenvuelve 68.

Así como ocurre con todos los derechos humanos, los niños tienen, sin excepción, los mismos derechos que emanan de su condición de tales y mientras lo sean, sin importar el contexto particular en que se encuentren. No obstante, no todos tienen el mismo interés superior lo que necesariamente va a marcar diferencias en la toma de decisiones a su respecto. Por ende, la tarea de definir el interés superior de cada NNA que interviene en un proceso judicial queda en manos del juez llamado a conocer y resolver el caso, decisión que, por una parte, no puede ser arbitraria ni inmotivada, y por otra, siempre debe tender a la maximización de sus derechos humanos.

\section{Algunas adecuaciones específicas al debido proceso}

De todo lo expuesto supra, se constata que tanto las garantías del debido proceso como los derechos de la infancia - o si se prefiere, el ISN - tienen la capacidad de avenirse a circunstancias diversas. Esto permite la configuración de procesos judiciales que sin dejar de ser debidos -es decir, respetuosos de los derechos intraprocesales de los justiciables y, por ende, adecuados para tutelar sus derechos sustanciales - sean acordes con los derechos humanos de

\footnotetext{
${ }^{64}$ Comité de los Derechos del Niño (2013), párrs. 27-29.

${ }^{65}$ Cumbre Judicial Iberoamericana (2014), p. 27. En idénticos términos, también, Poder Judicial de la República de Chile (2020), p. 35 .

${ }^{66}$ Rivero (2007), p. 91.

${ }^{67}$ Ravetllat (2018), p. 1332.

${ }^{68}$ Poder Judicial de la República de Chile (2020), p. 35.
} 
los NNA y su interés superior, pudiendo realizarse ajustes a favor de la infancia que no afecten el núcleo esencial del debido proceso.

Así, tanto desde el nivel central estatal como por parte de cada juez particular se deben tomar las previsiones para que en todos los procesos judiciales y en cada fase de ellos se atienda a las necesidades de los NNA y se propenda a su satisfacción ${ }^{69}$, sin que esto pueda calificarse como un trato discriminatorio hacia los intervinientes adultos del mismo proceso. En efecto, esto debe entenderse como la búsqueda de una igualdad real de oportunidades al interior de un proceso en que se permite que todos tengan las mismas posibilidades de hacer valer sus derechos. Por consiguiente, no es posible un debido proceso sin respeto y garantía hacia todos los derechos de los NNA.

En esa perspectiva, y como punto de partida, se ha resaltado la importancia de que los NNA, de acuerdo con su nivel de desarrollo, tengan acceso a información relativa al proceso en que les corresponde intervenir, cualquier sea el rol que deban desempeñar ${ }^{70}$. En este sentido, cada vez que resulte oportuno - tanto antes de su inicio como durante las distintas etapas de la sustanciación del juicio- se deben tomar las providencias para informar en un lenguaje simple y claro, comprensible para el menor de edad, diversos aspectos sobre el contenido del proceso, la importancia de su intervención en él y el resultado que se espera alcanzar, tomando especiales recaudos, como veremos, en el contenido de la sentencia ${ }^{71}$. La accesibilidad de esta información resulta capital para el ejercicio de todos los derechos de NNA, sin la cual se tornan completamente ilusorias dos de las garantías que integran el debido proceso y que se abordarán a continuación: el derecho a la prueba y a la sentencia motivada.

\subsection{EL DERECHO A LA PRUEBA DESDE LA ÓPTICA DE LOS DERECHOS DE LA INFANCIA}

Para estar en condiciones de sostener que se respetan cabalmente las garantías del debido proceso debe existir un efectivo ejercicio del derecho a la prueba, pues este está íntimamente vinculado con el derecho de defensa y la igualdad de armas que se debe producir entre todas las partes del proceso ${ }^{72}$. De lo contrario, difícilmente el resultado alcanzado podrá calificarse de

\footnotetext{
${ }^{69}$ Cumbre Judicial Iberoamericana (2014), p. 34.

${ }^{70}$ En este sentido, ver las Directrices 19 y 20 contenidas en Consejo Económico y Social de las Naciones Unidas, Resolución 2005/20, de 22 de julio de 2005. También ver, Comité de los Derechos del Niño (2013), párr. 15 letra g).

${ }^{71}$ Poder Judicial de la República de Chile (2020), p. 36.

${ }^{72}$ Nieva (2014), p. 150. Asimismo, Rivera (2011), p. 160.
} 
razonable y justo ${ }^{73}$, ya que el derecho a la prueba es uno de los engranajes del sistema que debe funcionar de manera óptima durante la tramitación de los procesos.

Por derecho a la prueba debemos entender aquel derecho subjetivo que poseen todos los justiciables y que les permite utilizar todos los medios de prueba que estimen pertinentes para establecer la veracidad (realidad) de los hechos discutidos en el proceso o bien para alcanzar la convicción del sentenciador, de modo que cumpliéndose los requisitos y formalidades legales ${ }^{74}$, estos medios de prueba deberán ser admitidos, practicados y valorados adecuadamente ${ }^{75}$. Siguiendo los postulados generales sobre igualdad y no discriminación que debe existir entre los justiciables, en principio ninguno de ellos debe tener privilegios o desventajas en materia probatoria. Es decir, todas las partes del juicio deben contar con las mismas oportunidades para ejercer su derecho a la prueba en sus distintas aristas, que van desde el ofrecimiento de los medios de prueba hasta la valoración razonada y lógica que de ellos debe llevar a cabo el sentenciador ${ }^{76}$.

En todo caso, se debe mencionar que este derecho fundamental no es absoluto ${ }^{77}$, pues su ejercicio concreto depende de las decisiones que a su respecto adopte el legislador (lo que permite calificarlo como un derecho de "configuración legal"78), que sin afectar su núcleo esencial, tiene libertad para determinar las condiciones, requisitos y formalidades con que deberá ser ejercido. Empero, más allá de la regulación específica, es evidente que a su respecto no caben interpretaciones rígidas y excesivamente formalistas, que le impidan desplegar su máxima vigencia ${ }^{79}$, la que incluso — siguiendo a Picó i Junoy - debe anteponerse a principios como la economía, la celeridad o la eficacia del proceso ${ }^{80}$. Por consiguiente, en la línea de lo que propugna el principio favor persona contenido en el art. 29 letra b) de la CADH, la interpretación de las normas que regulan el derecho a la prueba deben permitir obtener el mayor goce y ejercicio de los derechos humanos ${ }^{81}$ (o bien, tratándose de NNA, la mayor satisfacción del ISN82). Así, en cada caso concreto, los jueces deben actuar con la suficiente flexibilidad para permitir que la prueba de las partes pueda practicarse ${ }^{83}$, obviamente velando por el derecho a la defensa

\footnotetext{
${ }^{73}$ Morales (2013), p. 259.

${ }^{74}$ Marinoni y Cruz (2015), pp. 306-309.

75 Picó i Junoy (1996), pp. 18-25. En el mismo sentido, Morales (2013), p. 261.

${ }^{76}$ Morales (2013), p. 270.

${ }^{77}$ Picó i Junoy (2012), p. 178.

${ }^{78}$ De la Oliva et al. (2019), p. 173.

${ }^{79}$ Rivera (2011), p. 159.

${ }^{80}$ Picó i Junoy (2012), p. 178.

${ }^{81}$ Aguilar y Nogueira (2016), p. 17. Asimismo, Sagüés (1998), p. 6.

${ }^{82}$ Comité de los Derechos del Niño (2013), párr. 6 letra b). En el mismo sentido, Corte IDH, Caso Ramírez Escobar y Otros vs. Guatemala, de 9 de marzo de 2018, párr. 215.

${ }^{83}$ Morales (2013), p. 262.
} 
y los principios de contradicción y de audiencia en relación con el resto de los litigantes, de modo de evitar que se suscite cualquier situación de indefensión ${ }^{84}$. La determinación precisa de ese punto de equilibrio será una de las tareas más importantes para el juez de la causa en esta materia, particularmente en procesos judiciales en los que interviene un NNA -aunque, necesariamente esto se aplica en idénticos términos a cualquier persona en situación de vulnerabilidad-.

De esta manera, los objetivos perseguidos por el derecho a la prueba, en particular, y el debido proceso, en general, proscriben cualquier formalismo excesivo que termine por cercenar la efectividad de estos derechos, de modo que el juzgador siempre debe tener en consideración el principio pro probatione ${ }^{85}$. En esta perspectiva, se ha destacado la necesidad de satisfacer el derecho a la prueba sin incurrir en situaciones en que termine siendo obstaculizado o lisa y llanamente desconocido, de modo que, v. gr. ante la duda de admitir o no un medio de prueba, se debe optar por lo primero, más aún en modelos probatorios inspirados por la libertad probatoria y la sana crítica, tal como los que se han ido imponiendo progresivamente en todas las sedes procesales en Chile.

Ahora bien, uno de los aspectos más complejos del derecho a la prueba en relación con la infancia, lo constituye la práctica de las declaraciones personales de los NNA, sea que las presten como partes directas del pleito o como testigos de los hechos discutidos. Sobre este medio de prueba, se ha destacado que las inhabilidades para declarar como testigo que se basan, entre otras razones, en cuestiones etarias, buscan fortalecer la fiabilidad de los testimonios (medio de prueba que, como es sabido, cuenta de entrada con una serie de debilidades ${ }^{86}$ ). Sin embargo, se ha tendido a abrir la participación de los niños desempeñando este rol en el proceso, sin pedir juramento ${ }^{87}$, resguardando debidamente la forma del interrogatorio y la especialización de las personas que estarán a cargo de él88. En todo caso, resulta innegable que si la prueba de testimonios levanta desde ya desconfianzas, más aún lo hará cuando se trate de niños, tal como se ha relevado desde la psicología del testimonio ${ }^{89}$.

\footnotetext{
${ }^{84}$ Esparza (1995), p. 188.

${ }^{85}$ Morales (2013), p. 269.

${ }^{86}$ Contreras (2015), pp. 167-173.

${ }^{87}$ En Chile se excluye a los menores de prestar juramento. Así ocurre en el proceso civil (357 CPC), en el proceso penal (art. 306

CPP) y en el proceso de familia (art. 38 Ley $N^{\circ} 19.968$ ). Lo mismo sucede en España (art. 365 LEC) y en Colombia (art. 220 CGP).

${ }^{88}$ Rivera (2011), p. 187.

89 Por todos, Manzanero (2010), pp. 201-245.
} 
Por regla general, en la práctica de las declaraciones personales rige plenamente la publicidad de las actuaciones judiciales, no solo para las partes, sino también para los terceros. No obstante, tratándose de las declaraciones de NNA prestadas en el ámbito judicial ${ }^{90}$, existe total consenso en que la colisión entre, por un lado, el principio de publicidad hacia el público general y, por otro, el ISN y su derecho a la intimidad y honra — sin siquiera mencionar las vulneraciones que se le podrían provocar ante el desvelamiento total de su identidad y los detalles del conflicto en que está inmerso ${ }^{91}$-, el primero debe ceder ante estos ${ }^{92}$, no solo porque la publicidad es solo una regla técnica de configuración de los procesos judiciales ${ }^{93}$, sino, y más importante que eso, porque la finalidad del escrutinio y control ciudadano sobre el ejercicio del poder jurisdiccional en caso alguno puede trastocar los derechos de la infancia ${ }^{94}$, de modo que la publicidad adquiere un nuevo carácter cuando se trata del enjuiciamiento de NNA 95.

De esa forma, se debe evitar a toda costa revelar la identidad del niño a través de los medios de comunicación, deber que no solo afecta a los órganos estatales, sino también al resto de intervinientes del proceso. Además, es imprescindible tomar todas las medidas para que la actuación se desarrolle en un espacio privado, especialmente acondicionado para una diligencia infantil, contando solo con las personas indispensables para la obtención del testimonio y que por ley pueden o deben estar presentes, y - aunque sea un perogrullada - sin la concurrencia de aquellos que podrían afectar al niño, intimidarlo o hacerle sentir amenazado de cualquier manera ${ }^{96}$. Desde igual óptica, y con la finalidad de proteger la intimidad y el bienestar de los NNA, se ha indicado que de ser necesario se deberán ocultar los rasgos o la descripción física del NNA que preste testimonio, para lo cual podrá usarse una pantalla opaca o emplear medios de alteración de la imagen o de la voz ${ }^{97}$.

Por cierto, estas declaraciones se deben prestar con algunas condiciones mínimas que garanticen la no afectación de los derechos del NNA. Así, se ha sostenido que las personas encargadas de llevarla a cabo (jueces, psicólogos, etc.) deben comenzar la diligencia

\footnotetext{
${ }^{90}$ Particularmente, respecto a las declaraciones de niños víctimas y testigos de delitos, ver Consejo Económico y Social de las Naciones Unidas, Resolución 2005/20, de 22 de julio de 2005, apartado X, “Derecho a la intimidad", que establece las Directrices sobre la justicia en asuntos concernientes a los niños víctimas y testigos de delitos.

${ }^{91}$ En este sentido, y en relación la victimización secundaria a que se puede ver expuesto el niño-víctima, ver Fábrega (2019), pp. 20-21.

${ }^{92}$ Ferrer (2015), p. 180. En el mismo sentido, Álvarez (2011), pp. 29-31.

${ }_{93}$ Contreras (2015), pp. 72-74.

${ }^{94}$ De hecho, se ha puesto el acento en la necesidad de atender al ISN y evitar al niño toda clase de sufrimiento o daño que pueda gravitar sobre su vida futura. Corte IDH, Opinión Consultiva OC-17/2002, de 28 de agosto de 2002, párr. 134. Ver también Corte IDH, Caso V.R.P., V.P.V. y Otros vs. Nicaragua, de 8 de marzo de 2018, párr. 167.

${ }_{95}$ García (2006b), p. 1168.

${ }^{96}$ Cumbre Judicial Iberoamericana (2014), p. 47.

${ }^{97}$ Poder Judicial de la República de Chile (2020), p. 42.
} 
transmitiendo al declarante una sensación de calma y confort, expresándole el valor y la importancia del relato que prestará y explicándole claramente que no es obligación saber todas las respuestas, que solo se espera que cuente lo que sabe sobre los hechos (no hay respuestas incorrectas) y que no se verá expuesto a ninguna sanción por participar en la diligencia o por no conocer algún hecho98. En el mismo sentido, se debe explicar al NNA que no está obligado a declarar, que de hacerlo puede poner término a su testimonio cuando lo desee, que puede formular todas las preguntas que quiera y adicionar información o corregir lo que ha señalado si estima que es necesario ${ }^{99}$.

Lo anterior colisiona claramente con el contenido del derecho a la prueba de los otros litigantes, al menos tal como este se ha entendido para el caso de litigios llevados a cabo entre adultos. En efecto, lo normal es que los testimonios se presten de forma pública y directa en la sala de audiencias, donde los litigantes tienen contacto y comunicación directa con el declarante. De hecho, se estima que parte integrante e inextirpable del derecho a la prueba es la posibilidad de confrontar la prueba contraria, es decir, para estos efectos, examinar a los declarantes o testigos en una vista pública y mediante un debate contradictorio ${ }^{100}$, a fin de cuestionar la exactitud y honestidad de sus declaraciones ${ }^{101}$. Esta posibilidad de confrontación se considera el elemento principal para maximizar la calidad de la información que por esta vía ingresa al proceso, pues a través de ella se podrían develar errores, vacíos, engaños y otros defectos en la información proporcionada por el declarante ${ }^{102}$.

De hecho, la Corte IDH ha indicado que el principio de contradictorio en las actuaciones es uno de los elementos que permite el equilibrio entre las partes para la defensa de sus intereses y derechos ${ }^{103}$. Esto significa que el inculpado tiene a derecho a examinar en las mismas condiciones a los testigos a favor y en contra, de modo que ejercer su defensa ${ }^{104}$, y por cierto, su intervención en el análisis de las pruebas ${ }^{105}$.

\footnotetext{
${ }^{98}$ Contreras (2019), p. 351.

${ }^{99}$ Cumbre Judicial Iberoamericana (2014), pp. 43-44.

${ }^{100}$ Miranda (2018), p. 324.

${ }^{101}$ Ovejero (2019), pp. 241 y ss. Sobre el contraexamen de testigos, ver, Decap (2019), pp. 238-249.

102 Duce et al. (2011), pp. 230-231.

${ }^{103}$ Corte IDH, Opinión Consultiva OC-17/2002, de 28 de agosto de 2002, párr. 132. En idéntico sentido, Corte IDH, Caso Rodríguez Revelorio y Otros vs. Guatemala, de 14 de octubre de 2019, párr. 104; y Corte IDH, Caso Girón y Otro vs. Guatemala, de 15 de octubre de 2019, párr. 96.

${ }^{104}$ Corte IDH, Caso Palamara Iribarne vs. Chile, de 22 de noviembre de 2005, párr. 178.

${ }^{105}$ Corte IDH, Caso Barreto Leiva vs. Venezuela, de 17 de noviembre de 2009, párr. 54. También, Corte IDH, Caso Álvarez Ramos vs. Venezuela, de 30 de agosto de 2019, párr. 153.
} 
Por cierto, esta posibilidad de confrontación también existe tratándose de un declarante NNA, pero no se puede llevar a cabo de la misma forma en que se hace respecto de un adulto, atendidos los peligros de afectación o vulneración de derechos a que se podría ver expuesto el niño declarante. Obviamente, esto puede configurar una nueva colisión de derechos tratándose de conflictos de naturaleza penal, esta vez entre los derechos de la infancia y la presunción de inocencia, cuestión que representa quizá el mayor desafío para todo el sistema ${ }^{106}$. Esto básicamente podría producirse debido a las limitaciones de contradicción que pueden darse respecto de estas evidencias ${ }^{107}$, lo que provocaría que la defensa del acusado no tenga a su disposición todas las herramientas para restar mérito o poner a la vista las debilidades del testimonio prestado por el NNA — tal como podría hacerse tratándose de un adulto-, lo que posteriormente redundará en la determinación del valor de esa declaración y la subsecuente desvirtuación de la presunción de inocencia.

\subsection{EL DERECHO A LA SENTENCIA MOTIVADA EN CLAVE DE INFANCIA}

En la emisión del juicio jurisdiccional, es decir, en el pronunciamiento de la decisión del pleito y la comunicación de la solución del conflicto por la que ha optado el juez del caso, es donde se evidencia de forma más patente la materialización de las garantías del debido proceso. De hecho, en la sentencia se debe concretar el anhelo de una decisión justa para el conflicto específico, objetivo para cuya consecución colaboran todos los elementos del debido proceso que se tendrían que haber observado durante la sustanciación del juicio.

Empero, como se sabe, no cualquier decisión jurisdiccional puede estimarse adecuada o suficiente para el caso particular. Es necesario que ella cumpla con ciertos requisitos mínimos que permitan considerarla como una expresión legítima del ejercicio del poder estatal en este ámbito, y no un mero fruto de la discrecionalidad o irracional judicial ${ }^{108}$. Así, la motivación de las decisiones juega un rol fundamental tanto para la legitimación de las decisiones como para la eliminación de los espacios de arbitrariedad del juzgador ${ }^{109}$. Por consiguiente, el deber de motivación constituye una de las contrapartidas nucleares del derecho al debido proceso que

\footnotetext{
106 Fábrega (2019), pp. 21-23.

107 Miranda (2018), pp. 360-370.

${ }_{108}$ García y Contreras (2013), pp. 256 y 257.

${ }^{109}$ Rivera (2011), p. 375. En esta perspectiva, la Corte IDH ha destacado la importancia del pronunciamiento de decisiones debidamente fundamentadas como instrumento para evitar que se incurra en arbitrariedades: Corte IDH, Opinión Consultiva OC21/14, de 19 de agosto de 2014, párr. 137; Corte IDH, Caso Maldonado Ordoñez vs. Guatemala, de 3 de mayo de 2016, párr. 71; Corte IDH, Caso Maldonado Ordoñez vs. Guatemala, de 3 de mayo de 2016, párr. 87; Corte IDH, Caso V.R.P., V.P.V. y Otros vs. Nicaragua, de 8 de marzo de 2018, párr. 254; y Corte IDH, Caso Ramírez Escobar y Otros vs. Guatemala, de 9 de marzo de 2018, párr. 187.
} 
ampara a cada uno de los ciudadanos que comparecen ante los tribunales de justicia110, particularmente en lo relacionado con su derecho de defensa111.

Este deber implica que el juez se encuentra en la necesidad de exponer en su sentencia las razones, causas o justificaciones que lo han impulsado a adoptarla, vale decir, a expresar los motivos que lo han conducido a elegir una de las posibles soluciones que se le han propuesto o que estima pertinentes para el caso planteado112. Lo importante, como resalta Taruffo, está no solo en que la motivación sea un discurso justificativo de la decisión judicial que ha sido dictada, sino además, en que dicho discurso sea idóneo para fundarla racionalmente ${ }^{113}$. A partir de ahí, se entiende que la motivación equivale a la exposición del razonamiento que sirve de sostén a las decisiones judiciales ${ }^{114}$, de modo que el derecho a la sentencia motivada consiste en el derecho de los justiciables a que el juzgador exteriorice —en el contenido de la resolución — las buenas razones que lo llevaron a adoptar una decisión ${ }^{115}$, de forma congruente y razonable116.

En todo caso, no debe perderse de vista que el deber de motivación no se satisface con la expresión de cualquier tipo de fundamentación para la sentencia pronunciada. Esto significa, que si bien no se exige que el órgano jurisdiccional proporcione una argumentación excesivamente detallada de cada una de las alegaciones de las partes ${ }^{117}$, pues ello podría resultar inútil e innecesario, este deber tampoco se satisface con la exposición de generalidades o explicaciones vagas sobre lo decidido. Para cumplir cabalmente su función de garantía procesal, la motivación debe ser completa, en el sentido que comprenda todos los hechos que son objeto del proceso y todas las pruebas que han sido aportadas, dando cuenta de la exposición del conjunto de inferencias racionales, lógicas y correctas que permitan discurrir desde las premisas a la conclusión ${ }^{118}$, o sea, la enunciación del cuerpo argumentativo racional y complejo que conduce a la decisión judicial119.

\footnotetext{
${ }^{110}$ Aunque también se ha visto como una garantía constitucional originada a partir de que el Estado se reserva el ejercicio de la jurisdicción y prohíbe a los individuos todo acto de autotutela, Aliste (2011), p. 138.

111 Nieva (2014), p. 156.

112 Rodríguez (2003), p. 30.

${ }^{113}$ Taruffo (2011), p. 250.

${ }^{114}$ Rivera (2011), p. 352.

${ }^{115}$ Atienza (2013), p. 152. Para un decálogo de la motivación, ver en la misma obra, pp. 152-154. También, Abel (2016), pp. 68-69.

En el mismo sentido, Milione (2015), p. 150.

${ }^{116}$ Nieva (2014), p. 156.

117 Picó i Junoy (2012), p. 78.

118 Por eso, correctamente se ha afirmado que " $[1]$ as resoluciones judiciales que contengan contradicciones internas, arbitrariedades o errores lógicos que las conviertan en manifiestamente irrazonables, aun teniéndola se las considerará carentes de motivación, y por lo tanto vulnerarán el derecho a la tutela judicial efectiva". Esparza (1995), p. 224.

${ }^{119}$ Aliste (2011), pp. 156 y 241.
} 
La motivación de las sentencias judiciales tiene como destinatarios a las partes directas del proceso, a otros órganos jurisdiccionales y a la ciudadanía en general ${ }^{120}$, lo que permite sostener que posee distintas funciones y objetivos, aunque todos ellos están estrechamente vinculados con el control de la actividad jurisdiccional y la interdicción de la arbitrariedad ${ }^{121}$. En esta perspectiva, a los justiciables les permite conocer el ejercicio racional llevado a cabo por el juzgador para el establecimiento de los hechos y la aplicación de las normas jurídicas que se han estimado adecuadas a la resolución del asunto, descartando que ello sea producto del voluntarismo o la subjetividad 122 .

De esta forma, se podrán presentar dos opciones respecto a cada uno de los litigantes: que acepten la sentencia o bien que consideren que ella está errada y, por tanto, emplean alguno de los mecanismos de impugnación que contempla el ordenamiento jurídico ${ }^{123}$. Evidentemente, ambos caminos parten del mismo punto: el cabal conocimiento y comprensión del contenido de la sentencia por los justiciables. Y aquí es precisamente donde debe ponerse especial atención tratándose de NNA, pues si estos objetivos que ya son especialmente complejos para cualquier persona no letrada, ellos representan todo un reto tratándose de litigantes NNA.

Lo normal será que las resoluciones judiciales estén elaboradas por y para abogados, de manera que en ellas subyace una lógica y exposición de ideas y conceptos que solo es familiar y comprensible para quienes tienen conocimientos jurídicos. Por cierto, esto fenómeno no es privativo de la actividad jurisdiccional, sino que puede apreciarse en todas las áreas científicas y de conocimiento, e incluso parece justificado dada la complejidad de gran parte de los asuntos que se someten a la decisión de los tribunales, que demandan el análisis de normas legales que podrán contener los consabidos conceptos jurídicos de textura abierta一, de decisiones de otros órganos jurisdiccionales, nacionales e internacionales, e incluso de los aportes doctrinales en la materia —usualmente expuestos en términos eruditos y elevados-.

Empero, los destinatarios de la sentencia no son los órganos de la administración de justicia ni los letrados que representen a los ciudadanos en el pleito, sino las partes mismas. Son ellas quienes deben poder acceder al contenido de la decisión y comprenderlo, pues —aunque sea obvio decirlo- son quienes se verán personalmente afectadas por lo decidido. De ahí que,

\footnotetext{
${ }^{120}$ A partir de lo cual se distingue entre la función endo y extraprocesal de la motivación. Por todos, ver, Taruffo (2011), pp. 335349.

121 García y Contreras (2013), pp. 269 y 270. Sin dejar de mencionar, que se ha señalado que la motivación también cumple la misi ón de orientar las conductas sociales. Marinoni et al. (2018), p. 122.

122 Milione (2015), p. 153.

${ }^{123}$ Rivera (2011), p. 347.
} 
tratándose de procesos judiciales en que intervengan NNA, la sentencia debe considerar esta simple pero esencial garantía: la decisión debe estar sustentada en motivos fácilmente comprensibles para ellos, de modo que, de acuerdo con su nivel de desarrollo puedan entender el resultado del proceso, especialmente cuanto este sea adverso a sus intereses. De hecho, esta no puede ser entendida como una concesión graciosa de la autoridad hacia los NNA, sino todo lo contrario, pues los niños tienen derecho a conocer claramente la decisión del proceso en el que han estado inmersos.

Para el objetivo planteado, el lenguaje empleado en la sentencia así como la estructura formal y argumentativa contenida en ella juegan un papel protagónico, pues en concreto los jueces deberán ser capaces de expresar por escrito u oralmente, en las audiencias del proceso, la decisión de una forma que resulte comprensible para los NNA. No obstante, como todo, esta no es una tarea simple, pues exige conciliar el rigor y la precisión técnica de una decisión que sigue siendo un acto jurídico procesal, revisable por instancias superiores y que cumple funciones más allá del proceso en que es dictada, con la necesidad de que ella sea accesible para los NNA involucrados. De hecho, esto podría redundar en que iniciativas como la política de lenguaje claro que se ha impulsado en varias latitudes no sean suficientes para alcanzar el objetivo. Quizá se requiere la generación de un nuevo acto procesal que permita hacer efectivo el derecho a la sentencia motivada para NNA, o que en estos procesos, además de la sentencia usual, sea oportuno generar también una segunda versión de ella, adaptada para los niños destinatarios de ella. $\mathrm{O}$ bien, es menester generar un acto procesal de notificación y comunicación comprensible para los NNA implicados. Pero más allá de eso, lo que sí es claro, es que urge una adecuación normativa en este aspecto a fin de permitir una mayor y mejor vigencia de esta garantía fundamental del debido proceso.

\section{Reflexiones finales}

En época reciente hemos sido testigos de notables avances en el reconocimiento y la protección del ISN y de los derechos humanos de todos los NNA. La entrada en vigencia de la CDN marcó un punto de inflexión que significó incorporar tanto una nueva mirada hacia la infancia como el deber de todos los sectores de velar por la protección integral de los derechos de la niñez. Obviamente esto también debe tener un correlato efectivo en el funcionamiento del aparato jurisdiccional y la sustanciación de los procesos judiciales, de modo que durante la intervención de cualquier NNA se cuente con los mecanismos para resguardar plenamente sus 
derechos. Esto no es nada nuevo. Los pronunciamientos de la Corte IDH a los que se ha hecho referencia a lo largo de estas páginas, dejan en claro que esta preocupación ha estado presente en las últimas décadas.

Así las cosas, y con ese telón de fondo, podemos cerrar este trabajo con las siguientes reflexiones:

1. Es obligación del Estado adoptar todas las medidas necesarias para asegurar la plena vigencia y ejercicio de los derechos humanos, lo que obviamente incluye el debido proceso y las garantías que lo componen, dado su carácter instrumental para la efectividad del resto de derechos esenciales.

2. Solo con el pleno cumplimiento de la obligación anterior será posible reconocer y respetar la dignidad de todas las personas, lo que implica llevar a cabo un trato igualitario y no discriminatorio para todos quienes intervienen en un proceso judicial. Empero, en caso alguno dicha pretendida igualdad podrá alcanzarse mediante la aplicación pareja de las garantías del debido proceso a todos los justiciables, pues puede generarse una situación de mayor desigualdad que la que se trataba de evitar. Por consiguiente, es dable adoptar medidas específicas y diferenciadas cuando lo exija la situación particular, especialmente cuando se trate de NNA.

3. En ese sentido, la legislación general y las autoridades gubernamentales deben ser capaces de reconocer las diferencias extraprocesales existente entre quienes participan de un proceso judicial, tal como sucede entre adultos y NNA. De esta manera, se deben realizar las adecuaciones procesales que sean oportunas y que - no debemos olvidar- se encuentran permitidas y amparadas por el contenido y los objetivos de las garantías del debido proceso.

4. A mayor abundamiento, la adecuación de las garantías procesales de NNA viene exigida por la obligación de brindar una protección y satisfacción integral a sus derechos esenciales por parte de los órganos estatales, lo que debe ajustarse estrictamente a los lineamientos fijados por el principio del ISN.

5. Así, respecto al derecho a la prueba no caben interpretaciones y aplicaciones rígidas y formalistas que obstaculicen su goce y ejercicio por parte de NNA, ni menos que ello sea fuente de vulneración de los demás derechos de la infancia o de su interés superior. En ese sentido, tanto la publicidad como las formas habituales de las diligencias probatorias deben ceder y 
adecuarse a las particularidades que demanda la presencia de infantes en el proceso. Por ende, en todo proceso judicial en el que v. gr. participe un NNA como declarante, se debe resguardar su identidad, el espacio físico en que se lleva a cabo la diligencia, las personas que intervienen en ella y la forma en que se obtiene la declaración, a pesar de que ello pueda colisionar con los derechos de los adultos.

6. Por último, no puede desatenderse el derecho de todos los NNA a conocer claramente la decisión del pleito en que han participado, siendo esto expresión de su derecho a la sentencia motivada. Es más, la legislación procesal debería prever expresamente el mecanismo para que los NNA puedan acceder y comprender el contenido de las sentencias judiciales, de forma fácil y directa. Lo contrario es seguir cercenándoles el ejercicio de una garantía integrante del debido proceso.

\section{Bibliografía citada}

Abel Lluch, Xavier (2016): “Diez tesis sobre la valoración de la prueba, dos propuestas de lege ferenda y un decálogo sobre motivación”, en Agudelo Mejía, Dimaro; Pabón Giraldo, Liliana; Toro Garzón, Luis; Bustamante Rúa, Mónica y Vargas Vélez, Orión (coordinadores), El derecho probatorio y la decisión judicial (Medellín, Universidad de Medellín), pp. 41-71.

Agudelo Ramírez, Martín (2005): “El debido proceso”, en Opinión Jurídica (Vol. 4, № 7), pp. 89105.

Aguilar Cavallo, Gonzalo (2008): “El principio del interés superior del niño y la Corte Interamericana de Derechos Humanos”, en Estudios Constitucionales (Vol. 6, № 1), pp. 223247.

Aguilar Cavallo, Gonzalo y Nogueira Alcalá, Humberto (2016): “El principio favor persona en el derecho internacional y en el derecho interno como regla de interpretación y de preferencia normativa", en Revista de Derecho Público (Vol. 84), pp. 13-43.

Aliste Santos, Tomás-Javier (2011): La motivación de las resoluciones judiciales (Madrid, Marcial Pons). 
Álvarez Vélez, María Isabel (2011): “La protección del menor como límite a los derechos fundamentales", en Alcón Yustas, María Fuencisla y De Montalvo Jääskeläinen, Federico (coordinadores), Los menores en el proceso judicial (Madrid, Tecnos), pp. 15-32.

Atienza Rodríguez, Manuel (2013): Curso de argumentación jurídica (Madrid, Editorial Trotta).

Baeza Concha, Gloria (2001): “El interés superior del niño: Derecho de rango constitucional, su recepción en la legislación nacional y aplicación en la jurisprudencia”, en Revista Chilena de Derecho (Vol. 28, № 2), pp. 355-362.

Basset, Úrsula (2019): “Sutiles evoluciones de la comprensión de los derechos de la infancia: Niños y adolescentes ciudadanos en el siglo XXI", en Domínguez Hidalgo, Carmen (editora), Convención Internacional de los Derechos del Niño. Estudios y experiencias en Chile y Latinoamérica a 30 años de su vigencia (Santiago, Thomson Reuters), pp. 65-81.

Bobbio, Norberto (1991): El tiempo de los derechos (Trad. Rafael de Asís Roig, Madrid, Editorial Sistema).

Carmona Tinoco, Jorge (2014): "La articulación de los estándares de fuente interna e internacional del debido proceso", en Pérez Vásquez, Carlos (coordinador), El derecho humano al debido proceso. Sus dimensiones legal, constitucional y convencional (Valencia, Tirant lo Blanch), pp. 33-53.

Cillero Bruñol, Miguel (2007): “El interés superior del niño en el marco de la Convención Internacional sobre los Derechos del Niño", en Justicia y Derechos del Niño, UNICEF, Santiago de Chile ( ${ }^{\circ} 9$ ), pp. 125-142.

Comité de los Derechos del Niño (2013): “Observación General N¹4 sobre el derecho del niño a que su interés superior sea una consideración primordial, de 29 de mayo de 2013". [Disponible en: https://bit.ly/3ml6WJz]. [Fecha de consulta: 22 de septiembre de 2020].

Contreras Rojas, Cristian (2015): La valoración de la prueba de interrogatorio (Madrid, Marcial Pons).

(2019): “El testimonio infantil en la justicia de familia”, en Santibáñez Torres, María Elena (directora), La prueba en los procedimientos (Santiago, Thomson Reuters), pp. 339368. 
DEBIDO PROCESO E INFANCIA. LA PARTICIPACIÓN DE NIÑOS, NIÑAS Y ADOLESCENTES EN EL PROCESO JUDICIAL A LA LUZ DE LOS DERECHOS HUMANOS, CON ESPECIAL REFERENCIA AL DERECHO A LA PRUEBA Y EL DERECHO A LA SENTENCIA MOTIVADA EN CLAVE DE INFANCIA

Couture, Eduardo (1988): Introducción al estudio del proceso civil (Buenos Aires, Ediciones Depalma).

Cumbre Judicial Iberoamericana (2014): “Protocolo Iberoamericano de actuación judicial para mejorar el acceso a la justicia de personas con discapacidad, migrantes, niñas, niños, adolescentes, comunidades y pueblos indígenas, adoptado en la XVII Edición, Santiago de Chile". [Disponible en: https://bit.ly/3bg7f1R]. [Fecha de consulta: 21 de septiembre de 2020].

Decap Fernández, Mauricio (2019): La prueba de los hechos en el proceso penal (Santiago, DER Ediciones).

De la Oliva Santos, Andrés; Díez-Picazo Giménez, Ignacio y Vegas Torres, Jaime (2019): Curso de Derecho procesal civil I. Parte general, cuarta edición (Madrid, Editorial Universitaria Areces).

Domínguez Hidalgo, Carmen (2019): “La protección normativa de la infancia en Chile antes de la Convención de los Derechos del Niño: Mirada evolutiva y lecciones para el presente", en Domínguez Hidalgo, Carmen (editora), Convención Internacional de los Derechos del Niño. Estudios y experiencias en Chile y Latinoamérica a 30 años de su vigencia (Santiago, Thomson Reuters), pp. 3-18.

Duce J., Mauricio; Marín Verdugo, Felipe y Riego Ramírez, Cristián (2011): “Reforma de los procesos civiles orales consideraciones desde el debido proceso y calidad de la información”, en Pereira Campos, Santiago (coordinador), Modernización de la justicia civil (Montevideo, Universidad de Montevideo), pp. 177-248.

Escobar Gallardo, Paulina y Hernández Cádiz, María Victoria (2018): Interés superior del niño. Principio general del Derecho (Santiago, Editorial Hammurabi).

Esparza Leibar, Iñaki (1995): El principio del debido proceso (Barcelona, Bosch).

Fábrega Ruiz, Cristóbal (2019): “El maltrato de niños, niñas y adolescentes. Acercamiento desde la perspectiva de la actividad probatoria, en Reflexiones sobre la prueba judicial", en Araya Novoa, Marcela; Hermosilla Iriarte, Francisco y Cerda San Martín, Rodrigo 
(coordinadores), Homenaje a Profesor Manuel Miranda Estrampes (Santiago, Librotecnia), pp. 13-46.

Fajardo Morales, Zamir (2014): “Introducción”, en Pérez Vásquez, Carlos (coordinador), El derecho humano al debido proceso. Sus dimensiones legal, constitucional y convencional (Valencia, Tirant lo Blanch), pp. 17-31.

Ferrer Arroyo, Francisco (2015): "El debido proceso desde la perspectiva de la Corte Interamericana de Derechos Humanos", en Revista Jurídica de la Universidad de Palermo (Año 14, № 1), pp. 155-184.

García Pino, Gonzalo y Contreras Vásquez, Pablo (2013): "El derecho a la tutela judicial y al debido proceso en la jurisprudencia del Tribunal Constitucional chileno", en Estudios Constitucionales (Año 11, № 2), pp. 229-282.

García Ramírez, Sergio (2006a): "El debido proceso. Concepto General y regulación en la Convención Americana sobre Derechos Humanos", en Boletín Mexicano de Derecho Comparado (Año XXXIX, № 117), pp. 637-670.

(2006b): "Panorama del debido proceso (adjetivo) penal en la jurisprudencia de la Corte Interamericana", en Anuario de Derecho Constitucional Latinoamericano, pp. 11111173 ,

Hoyos, Arturo (2004): El debido proceso (Bogotá, Temis).

Hoyos Castañeda, Ilva (2019): “La dignidad del niño: Fundamento del interés superior del niño, en Convención Internacional de los Derechos del Niño", en Domínguez Hidalgo, Carmen (editora), Estudios y experiencias en Chile y Latinoamérica a 30 años de su vigencia (Santiago, Thomson Reuters), pp, 43-63.

Ibáñez Rivas, Juana (2010): "Los derechos de los niños, niñas y adolescentes en la jurisprudencia de la Corte Interamericana de Derechos Humanos", en Revista Instituto Interamericano de Derechos Humanos (№ 51), pp. 13-54.

Letelier Loyola, Enrique (2013): El derecho fundamental al recurso en el proceso penal (Barcelona, Atelier). 
DEBIDO PROCESO E INFANCIA. LA PARTICIPACIÓN DE NIÑOS, NIÑAS Y ADOLESCENTES EN EL PROCESO JUDICIAL A LA LUZ DE LOS DERECHOS HUMANOS, CON ESPECIAL REFERENCIA AL DERECHO A LA PRUEBA Y EL DERECHO A LA SENTENCIA MOTIVADA EN CLAVE DE INFANCIA (en prensa): Crisis y desafíos de la tutela judicial efectiva en una sociedad multicultural (Colima, México, Doctorado en Derecho, Universidad de Colima).

Manzanero Puebla, Antonio (2010): Memoria de testigos. Obtención y valoración de la prueba testifical (Madrid, Ediciones Pirámide).

Marinoni, Luiz; Arenhart, Sérgio y Mitidiero, Daniel (2018): “Derecho fundamental al proceso justo: Derechos fundamentales procesales en el Brasil", en Mitidiero, Daniel; Nieva, Jordi; Oteiza, Eduardo; Priori, Giovanni; Ramírez, Diana María y Taruffo, Michele (coordinadores), Los principios procesales de la justicia civil en Iberoamérica (Lima, Palestra), pp. 79-136.

Marinoni, Luiz Guillherme y Cruz Arenhart, Sérgio (2015): La prueba (Trad. René Nüñez Ávila, Santiago, Thomson Reuters).

Milione, Ciro (2015): El derecho a la tutela judicial efectiva en la jurisprudencia del Tribunal Europeo de Derechos Humanos (Valencia, Tirant lo Blanch).

Miranda Estrampes, Manuel (2018): “Prueba testifical y garantía de contradicción en la jurisprudencia del tribunal europeo de derechos humanos", Vásquez, Carmen (coordinadora), en Hechos y razonamiento probatorio (Pachuca de Soto, Editorial CEJI), pp. 317-386.

Morales Godó, Juan (2013): “Naturaleza constitucional del derecho a la prueba, en Proceso y Constitución", en Priori Posada, Giovanni (coordinador), Las garantías del justo proceso (Lima, Palestra), pp. 257-271.

Nieva Fenoll, Jordi (2014): Derecho procesal I. Introducción (Madrid, Marcial Pons).

Oteiza, Eduardo (2003): “El debido proceso. Evolución de la garantía y autismo procesal”, en AA.VV., Debido proceso (Santa Fe, Rubinzal-Culzoni), pp. 3-54.

Ovejero Puente, Ana María (2019): El derecho al juicio justo en el Convenio Europeo de Derechos Humanos (Valencia, Tirant lo Blanch).

Picó i Junoy, Joan (1996): El derecho a la prueba en el proceso civil (Barcelona, Bosch). (2012): Las garantías constitucionales del proceso, segunda edición (Barcelona, Bosch). 
Pinto Salazar, Jimena (2019): El niño: Sujeto de derechos procesales en la justicia de familia. El derecho a ser oído en Chile (Santiago, Editorial Hammurabi).

Poder Judicial de la República de Chile (2020): "Protocolo de acceso a la justicia de grupos vulnerables". [Disponible en: https://bit.ly/3EkDI3C]. [Fecha de consulta: 15 de octubre de 2020].

Priori Posada, Giovanni (2003): “La efectiva tutela jurisdiccional de las situaciones jurídicas materiales: hacia una necesaria reinvidicación de los fines del proceso", en Ius et Veritas (№ 26), pp. 273-292.

Quispe Remón, Florabel (2010): El debido proceso en el derecho internacional y en el sistema interamericano (Valencia, Tirant lo Blanch).

Ravetllat Ballesté, Isaac y Pinochet Olave, Ruperto (2015): “El interés superior del niño en el marco de la Convención Internacional sobre los Derechos del Niño y su configuración en el Derecho civil chileno", en Revista Chilena de Derecho (Vol. 42, № 3), pp. 903-934.

Ravetllat Ballesté, Isaac (2018): “El principio del interés superior del niño/a en el ordenamiento jurídico civil chileno: Hacia una objetivación del sistema”, en Lledó Yagüe, Francisco; Ferrer Vanrell, María Pilar; Torres Lana, José y Achón Bruñén María José (directores), Estudio Sistemático de la Ley 26/2015, de 28 de julio de modificación del sistema de protección de la infancia y a la adolescencia (Madrid, Dykinson), pp. 1329-1347.

Rivera Morales, Rodrigo (2011): La prueba: Un análisis racional y práctico (Madrid, Marcial Pons).

Rivero Hernández, Francisco (2007): El interés del menor, segunda edición (Madrid, Dykinson).

Rodríguez Boente, Sonia (2003): La justificación de las decisiones judiciales. El artículo 120.3 de la Constitución española (Santiago de Compostela, Editorial Universidad de Santiago de Compostela).

Sagüés, Néstor Pedro (1998): La interpretación de los derechos humanos en las jurisdicciones nacional e internacional (Buenos Aires, Academia Nacional de Derecho y Ciencias Sociales de Buenos Aires). 
Taruffo, Michele (1997): “Idee per una teoria della decisione giusta”, en Rivista Trimestrale di Diritto e Procedura Civile (Vol. 51, № 2), pp. 315-328.

(2011): La motivación de la sentencia civil (Trad. Lorenzo Córdoba Vianello, Madrid, Trotta).

Vargas Pavez, Macarena y Fuentes Maureira, Claudio (2019): Introducción al Derecho Procesal. Nuevas aproximaciones (Santiago, DER Ediciones).

\section{Jurisprudencia citada}

Corte IDH: Garantías judiciales en estados de emergencia (arts. 27.2, 25 y 8 Convención Americana sobre Derechos Humanos). Opinión Consultiva OC-9/87 de 6 de octubre de 1987.

Corte IDH: El derecho a la información sobre la asistencia consular en el marco de las garantías del debido proceso legal. Opinión Consultiva OC-16/99 de 1 de octubre de 1999.

Corte IDH: Caso Baena Ricardo y otros vs. Panamá. Fondo, Reparaciones y Costas. Sentencia de 2 de febrero de 2001.

Corte IDH: Condición Jurídica y Derechos Humanos del Niño. Opinión Consultiva OC-17/2002 de 28 de agosto de 2002.

Corte IDH: Caso Bulacio vs. Argentina. Fondo, Reparaciones y Costas. Sentencia de 18 de septiembre de 2003,

Corte IDH: Caso Instituto de Reeducación del Menor vs. Paraguay. Excepciones Preliminares, Fondo, Reparaciones y Costas. Sentencia de 2 de septiembre de 2004.

Corte IDH: Caso Comunidad Indígena Yakye Axa vs. Paraguay. Fondo, Reparaciones y Costas. Sentencia de 17 de junio de 2005.

Consejo Económico y Social de las Naciones Unidas. Resolución 2005/20, que establece las Directrices sobre la justicia en asuntos concernientes a los niños víctimas y testigos de delitos, de 22 de julio de 2005. 
Corte IDH: Caso Palamara Iribarne vs. Chile. Fondo, Reparaciones y Costas. Sentencia de 22 de noviembre de 2005.

Corte IDH: Caso González y Otras ("Campo Algodonero") vs. México. Excepción Preliminar, Fondo, Reparaciones y Costas. Sentencia de 16 de noviembre de 2009.

Corte IDH: Caso Barreto Leiva vs. Venezuela. Fondo, Reparaciones y Costas. Sentencia de 17 de noviembre de 2009.

Corte IDH: Caso de la Masacre de las Dos Erres vs. Guatemala. Excepción Preliminar, Fondo, Reparaciones y Costas. Sentencia de 24 de noviembre de 2009.

Corte IDH: Caso Atala Riffo y Niñas vs. Chile. Fondo, Reparaciones y Costas. Sentencia de 24 de febrero de 2012.

Corte IDH: Caso Furlan y Familiares vs. Argentina. Excepciones Preliminares, Fondo, Reparaciones y Costas. Sentencia de 31 de agosto de 2012.

Corte IDH: Caso Mendoza y Otros vs. Argentina. Excepciones Preliminares, Fondo y Reparaciones. Sentencia de 14 de mayo de 2013.

Corte IDH: Caso Familia Pacheco Tineo vs. Estado Plurinacional de Bolivia. Excepciones Preliminares, Fondo, Reparaciones y Costas. Sentencia de 25 de noviembre de 2013.

Corte IDH: Derechos y garantías de niñas y niños en el contexto de la migración y/o en necesidad de protección internacional. Opinión Consultiva OC-21/14 de 19 de agosto de 2014.

Corte IDH: Caso Maldonado Ordoñez vs. Guatemala. Excepción Preliminar, Fondo, Reparaciones y Costas. Sentencia de 3 de mayo de 2016.

Corte IDH: Caso V.R.P., V.P.V. y Otros vs. Nicaragua. Excepciones Preliminares, Fondo, Reparaciones y Costas. Sentencia de 8 de marzo de 2018.

Corte IDH: Caso Ramírez Escobary Otros vs. Guatemala. Fondo, Reparaciones y Costas. Sentencia de 9 de marzo de 2018.

Corte IDH: Caso Álvarez Ramos vs. Venezuela. Excepción Preliminar, Fondo, Reparaciones y Costas. Sentencia de 30 de agosto de 2019. 

REFERENCIA AL DERECHO A LA PRUEBA Y EL DERECHO A LA SENTENCIA MOTIVADA EN CLAVE DE INFANCIA

Corte IDH: Caso Rodríguez Revolorio y Otros vs. Guatemala. Excepción Preliminar, Fondo, Reparaciones y Costas. Sentencia de 14 de octubre de 2019.

Corte IDH: Caso Girón y Otro vs. Guatemala. Excepción Preliminar, Fondo, Reparaciones y Costas. Sentencia de 15 de octubre de 2019. 